\title{
Therapeutic and Clinical Outcomes of Robot-assisted Partial Nephrectomy Versus Cryoablation for T1 Renal Cell Carcinoma
}

\author{
TOSHIHIRO UEMURA ${ }^{1}$, TAIGO KATO ${ }^{1}$, AKIRA NAGAHARA ${ }^{2}$, ATSUNARI KAWASHIMA ${ }^{1}$, \\ KOJI HATANO ${ }^{1}$, TAKESHI UJIKE ${ }^{1}$, YUSUKE ONO ${ }^{3}$, HIROKI HIGASHIHARA ${ }^{3}$, KAZUTOSHI FUJTA ${ }^{1}$, \\ SHINICHIRO FUKUHARA ${ }^{1}$, HIROSHI KIUCHI ${ }^{1}$, RYOICHI IMAMURA ${ }^{1}$, \\ NORIYUKI TOMIYAMA ${ }^{3}$, NORIO NONOMURA ${ }^{1}$ and MOTOHIDE UEMURA ${ }^{1}$ \\ ${ }^{1}$ Department of Urology, Osaka University Graduate School of Medicine, Osaka, Japan; \\ ${ }^{2}$ Department of Urology, Osaka International Cancer Institute, Osaka, Japan; \\ ${ }^{3}$ Department of Radiology, Osaka University Graduate School of Medicine, Osaka, Japan
}

\begin{abstract}
Background: In cTl renal cell carcinoma (RCC), very few studies have compared oncological outcomes and renal function preservation rates in nephron-sparing robotassisted partial nephrectomy (RAPN) and percutaneous cryoablation (PCA). Patients and Methods: We retrospectively analysed 126 patients with cT1 RCC treated with RAPN $(n=78)$ and computed tomography-guided PCA (n=48) between March 2016 and November 2019. Clinical data and outcomes were compared for the two groups. Results: There were no significant differences in the 3-year overall survival and relapse-free survival rates in the two groups ( $p=0.17$ and $p=0.093$, respectively). The median percentage of estimated glomerular filtration rate preservation at 6 months after surgery was $91.8 \%$ and $91.4 \%$ in the RAPN and PCA groups, respectively ( $p=0.9)$. Conclusion: In patients with cTla RCC, oncological outcomes and renal function appear similar following RAPN and PCA.
\end{abstract}

With the progress of cancer screening methods and aging of the population, the number of patients with renal cell carcinomas (RCCs) has increased in recent years. Partial nephrectomy (PN) has been recognised as the standard treatment for small RCCs $(<7 \mathrm{~cm}$, cT1 tumour) because it provides optimal oncological outcomes and maintains better renal function than radical nephrectomy (1-4). Recently,

This article is freely accessible online.

Correspondence to: Taigo Kato (ORCID ID: 0000-0002-8681-1407), MD, Ph.D., Department of Urology, Osaka University Graduate School of Medicine, 2-2 Yamadaoka, Suita, Osaka, 565-0871, Japan. Tel: +81 668793531, Fax: +81 668793534, e-mail: kato@uro.med.oaska-u.ac.jp

Key Words: Cryoablation, renal cell carcinoma, renal function, robotassisted partial nephrectomy. robot-assisted PN (RAPN) has become an increasingly prevalent surgery because of the stability of surgical technique in tumour excision and improved suturing renorrhaphy with $3 \mathrm{D}$ visualization $(5,6)$. On the other hand, percutaneous cryoablation (PCA) has been validated as an alternative nephron-sparing therapy (NST) in patients with poor general condition and has shown favourable clinical results for the treatment of small RCCs, especially cT1a (7, 8 ). However, there are only a few reports comparing the preservation rate of renal function in RAPN and PCA cases.

The aim of this study was to assess the clinical outcomes of RAPN and PCA at our Institution during the same period, as well as preserved renal function following minimally invasive NST.

\section{Patients and Methods}

Patients. We retrospectively reviewed the records of 126 consecutive patients who had undergone RAPN $(n=78)$ or PCA $(n=48)$ between March 2016 and November 2019 at Osaka University Hospital. All patients underwent plain- and contrast-enhanced abdominal computed tomographic (CT) scans for RCC diagnosis and clinical staging. Supplementary magnetic resonance imaging was provided as needed for thorough evaluation of the tumour. Patients with favourable general conditions underwent RAPN, whereas PCA was performed for patients who were considered at high surgical risk due to comorbidities. Perioperative complications were evaluated using the Clavien-Dindo classification $(9,10)$.

Robot-assisted partial nephrectomy. Before surgery, we constructed 3D-images using multi-detector computed tomography and SYNAPSE VINCENT software (Fujifilm Medical Co., Ltd., Tokyo, Japan) to obtain information about the location of the tumour and blood vessels. RAPN using the retroperitoneal approach was performed for tumours located on the posterior side of the renal hilum. RAPN was performed using the da Vinci Surgical System (Intuitive Surgical, Sunnyvale, CA, USA) under general anaesthesia. The tumours were excised under warm ischaemia using complete renal arterial clamping. When the urinary tract was 
Table I. Patient characteristics.

\begin{tabular}{|c|c|c|c|c|}
\hline Parameters & & RAPN (n=78) & PCA $(n=48)$ & $p$-Value \\
\hline Age at operation, years & Median (IQR) & $61(52-69)$ & $78(70-82)$ & $<0.001$ \\
\hline $\mathrm{BMI}, \mathrm{kg} / \mathrm{m}^{2}$ & Median (IQR) & $23(21-25)$ & $23(21-26)$ & 0.49 \\
\hline \multirow[t]{2}{*}{ Gender, n (\%) } & Male & $63(81.0)$ & $41(85.4)$ & 0.5 \\
\hline & Female & $15(19.0)$ & $7(14.6)$ & \\
\hline \multirow[t]{2}{*}{ Laterality, n (\%) } & Left & $40(51.3)$ & $28(58.3)$ & 0.44 \\
\hline & Right & $38(48.7)$ & $20(41.7)$ & \\
\hline Kidney, n (\%) & Single & $0(0)$ & $2(4.2)$ & 0.048 \\
\hline \multirow[t]{3}{*}{ ASA score, n (\%) } & 1 & $59(75.6)$ & $2(4.2)$ & $<0.001$ \\
\hline & 2 & $18(23.1)$ & $30(62.5)$ & \\
\hline & 3 & $1(1.3)$ & $16(33.3)$ & \\
\hline Preoperative eGFR, $\mathrm{ml} / \mathrm{min} / 1.73 \mathrm{~m}^{2}$ & Median (IQR) & $73.2(64.0-84.4)$ & $53.6(36.4-61.3)$ & $<0.001$ \\
\hline Maximum tumour diameter, $\mathrm{mm}$ & Median (IQR) & $19(15-23)$ & $26(20-34)$ & $<0.001$ \\
\hline \multirow[t]{2}{*}{ Clinical T-stage, n (\%) } & $1 \mathrm{a}$ & $73(93.6)$ & $46(95.8)$ & 0.3 \\
\hline & $1 \mathrm{~b}$ & $5(6.4)$ & $2(4.2)$ & \\
\hline \multirow[t]{3}{*}{ R.E.N.A.L nephrometry score, n (\%) } & $\leq 6$ & $40(51.3)$ & $21(43.6)$ & 0.32 \\
\hline & $7-9$ & 35 (44.9) & $22(45.8)$ & \\
\hline & $\geq 10$ & $3(3.8)$ & $5(10.8)$ & \\
\hline \multirow[t]{6}{*}{ RCC subtype, n (\%) } & Clear cell & $58(74.3)$ & $41(85.4)$ & 0.23 \\
\hline & Papillary & $11(14.1)$ & $4(8.3)$ & \\
\hline & Chromophobe & $6(7.7)$ & $2(4.2)$ & \\
\hline & Oncocytoma & $2(2.6)$ & 0 & \\
\hline & AML & $1(1.3)$ & 0 & \\
\hline & Unknown & 0 & $1(2.1)$ & \\
\hline \multirow[t]{3}{*}{ Pathological T stage, $\mathrm{n}(\%)$} & $1 \mathrm{a}$ & $70(89.7)$ & & \\
\hline & $1 \mathrm{~b}$ & $4(5.1)$ & & \\
\hline & $3 a$ & $1(1.3)$ & & \\
\hline \multirow[t]{3}{*}{ Tumour grade, $\mathrm{n}(\%)$} & 1 & $29(37.2)$ & & \\
\hline & 2 & $40(51.3)$ & & \\
\hline & 3 & $6(7.7)$ & & \\
\hline Observation period, months & Median (IQR) & $18.5(12-30)$ & $12(6-32)$ & 0.039 \\
\hline \multirow[t]{2}{*}{ Patients recurrence, n (\%) } & With & $2(2.6)$ & $3(6.2)$ & \\
\hline & Without & $76(97.4)$ & $45(93.8)$ & \\
\hline \multirow[t]{2}{*}{ Death, n (\%) } & Cancer & $0(0)$ & $0(0)$ & \\
\hline & Other cause & $0(0)$ & $1(2.1)$ & \\
\hline
\end{tabular}

AML: Angiomyolipoma; ASA: American Society of Anesthesiologists; eGFR: estimated glomerular filtration rate; IQR: interquartile range; PCA: percutaneous cryoablation; no.: number; RAPN: robot-assisted partial nephrectomy; RCC: renal cell carcinoma. Statistically significant $p$-values are shown in bold.

opened, renal pelvic sutures were performed. All patients received parenchymal sutures.

We investigated trifecta (11) achievement (negative surgical margin, no postoperative complications and warm ischaemia time of $\leq 25 \mathrm{~min}$ ) in the RAPN group as an indicator of surgical quality.

Percutaneous cryoablation. Before starting PCA, all patients were confirmed to have RCC by needle biopsy. CT-guided PCA was performed using the CRYO-HIT System (Galil Medical Ltd, Yokneam, Israel) under local anaesthesia. Multiple 17-gauge probes (typically three) were percutaneously inserted under CT fluoroscopic guidance, and ice ball formation was monitored by CT to ensure a $>5 \mathrm{~mm}$ safety margin around the renal tumour. Two freezing and thawing cycles of PCA were routinely repeated to increase tumour cell injury. At 3 months after PCA, all patients underwent follow-up dynamic $\mathrm{CT}$ and needle biopsy to confirm the absence of residual tumours.
Follow-up. Follow-up was performed according to the institutional standard for local RCC, with clinical examination and laboratory testing at $1,3,6$, and 12 months, and analysis by CT every 3 months. The postoperative rate of preservation of estimated glomerular filtration rate (eGFR) was defined as postoperative eGFR/preoperative eGFR. In addition, we compared the overall (OS) and relapse-free (RFS) survival rates for RAPN and PCA. OS was defined as the time from RAPN or PCA to documented death or last contact, whereas RFS was defined as the time from RAPN or PCA to any local recurrence.

Statistical analysis. Clinical data are presented as the median and interquartile range (IQR). Multiple logistic regression analysis was used to evaluate factors associated with trifecta achievement in the RAPN group and decline in renal function at 6 months postoperatively $(12,13)$ in all patients. The cut-off value was determined by plotting the receiver operating characteristic curve. The Kaplan-Meier method was used to calculate survival rates 
Table II. Surgical results.

\begin{tabular}{|c|c|c|c|c|}
\hline Variable & & RAPN (n=78) & PCA $(n=48)$ & $p$-Value \\
\hline \multirow{2}{*}{ Approach, n (\%) } & Transperitoneal & $54(69.2)$ & & \\
\hline & Retroperitoneal & $24(30.8)$ & & \\
\hline Surgical time, min & Median (IQR) & $224(199-263)$ & & \\
\hline Console time, $\min$ & Median (IQR) & $138(98-176)$ & & \\
\hline Blood loss, ml & Median (IQR) & $10(0-100)$ & & \\
\hline Warm ischaemia time & Median (IQR) & $24.5(17-34)$ & & \\
\hline Surgical margin, $\mathrm{n}(\%)$ & Positive & $1(1.3)$ & & \\
\hline Trifecta achievement, n (\%) & Yes & $41(52.6)$ & & \\
\hline Clavien-Dindo complications, $\mathrm{n}(\%)$ & Grade $\geq 3$ & $2(2.6)$ & $1(2.1)$ & 0.86 \\
\hline Intraoperative complications, $\mathrm{n}(\%)$ & Bleeding requiring open conversion (grade 3) & $1(1.3)$ & & \\
\hline \multirow[t]{2}{*}{ Postoperative complications, n (\%) } & Pseudoaneurysm requiring embolization (grade 3) & $1(1.3)$ & & \\
\hline & Post-haemorrhagic requiring embolization (grade 3 ) & $1(2.1)$ & & \\
\hline eGFR preservation at 6 months, $\%$ & Median (IQR) & $91.8(82.4-100)$ & $91.4(85.7-99.3)$ & 0.9 \\
\hline
\end{tabular}

eGFR: Estimated glomerular filtration rate; IQR: interquartile range; PCA: percutaneous cryoablation; RAPN: robot-assisted partial nephrectomy.

Table III. Multiple logistic regression model for factors associated with trifecta achievement.

\begin{tabular}{|c|c|c|c|c|c|}
\hline \multirow[b]{2}{*}{ Variable } & & \multicolumn{2}{|c|}{ Univariate } & \multicolumn{2}{|c|}{ Multivariate } \\
\hline & & OR $(95 \% \mathrm{CI})$ & $p$-Value & OR $(95 \% \mathrm{CI})$ & $p$-Value \\
\hline Age & $\begin{array}{l}<60 \text { Years } \\
\geq 60 \text { Years }\end{array}$ & $\begin{array}{l}0.67(0.27-1.64) \\
\quad \text { Reference }\end{array}$ & 0.38 & & \\
\hline BMI & $\begin{array}{l}<23.5 \mathrm{~kg} / \mathrm{m}^{2} \\
\geq 23.5 \mathrm{~kg} / \mathrm{m}^{2}\end{array}$ & $\begin{array}{l}0.71(0.29-1.75) \\
\text { Reference }\end{array}$ & 0.46 & & \\
\hline ASA-PS & $\begin{array}{l}<2 \\
\geq 2\end{array}$ & $\begin{array}{l}1.41(0.50-3.98) \\
\text { Reference }\end{array}$ & 0.52 & & \\
\hline Preoperative eGFR & $\begin{array}{l}\geq 70 \mathrm{ml} / \mathrm{min} / 1.73 \mathrm{~m}^{2} \\
<70 \mathrm{ml} / \mathrm{min} / 1.73 \mathrm{~m}^{2}\end{array}$ & $\begin{array}{l}3.13(1.22-7.99) \\
\quad \text { Reference }\end{array}$ & 0.017 & $\begin{array}{l}2.66(0.93-7.63) \\
\text { Reference }\end{array}$ & 0.068 \\
\hline Maximum tumour diameter & $\begin{array}{l}<20 \mathrm{~mm} \\
\geq 20 \mathrm{~mm}\end{array}$ & $\begin{array}{l}2.72(1.08-6.86) \\
\text { Reference }\end{array}$ & 0.036 & $\begin{array}{c}1.70(0.60-4.80) \\
\text { Reference }\end{array}$ & 0.31 \\
\hline R.E.N.A.L. nephrometry score & $\begin{array}{l}<8 \\
\geq 8\end{array}$ & $\begin{array}{c}4.47(1.58-12.69) \\
\text { Reference }\end{array}$ & 0.0048 & $\begin{array}{c}4.20(1.38-12.54) \\
\text { Reference }\end{array}$ & 0.011 \\
\hline
\end{tabular}

ASA-PS: American Society of Anesthesiologists physical status; BMI: body mass index; CI: confidence interval; eGFR: estimated glomerular filtration rate; min: minute; OR: odds ratio. Statistically significant $p$-values are shown in bold.

and Iog-rank tests were used to compare the two groups. A value of $p<0.05$ was considered statistically significant. All statistical analyses were conducted using JMP software (version 15.0; SAS Institute, Cary, NC, USA).

\section{Results}

Patient characteristics. The clinical and pathologic characteristics are shown in Table I. The median age of the RAPN group was significantly lower than that of the PCA group $(p<0.001)$. The PCA group had significantly worse general conditions, as evaluated by the American Society of Anesthesiologists' score, than the RAPN group $(p<0.001)$. Median preoperative eGFR of the RAPN group was significantly better than that of the PCA group (73.2 $\mathrm{ml} / \mathrm{min} / 1.73 \mathrm{~m}^{2}$ versus $\left.53.6 \mathrm{ml} / \mathrm{min} / 1.73 \mathrm{~m}^{2}, p<0.001\right)$. No significant differences were identified between the two groups for clinical T-stage, R.E.N.A.L nephrometry score (14) or RCC subtype.

Perioperative outcomes. The surgical outcomes are shown in Table II. Fifty-four patients underwent RAPN using the transperitoneal approach, whereas 24 patients underwent RAPN using the retroperitoneal approach. The median operative time was $224 \mathrm{~min}(\mathrm{IQR}=199-263 \mathrm{~min})$. The median console time was $138 \mathrm{~min}(\mathrm{IQR}=98-176 \mathrm{~min})$. The median estimated blood loss was $10 \mathrm{ml}$ (IQR=0-100 ml). Trifecta was achieved in 41 patients $(52.6 \%)$ in the RAPN group. 
Table IV. Multiple logistic regression model for factors associated with a decline in estimated glomerular filtration rate (eGFR) of $10 \%$ or more at 6 months after surgery considering all patients.

\begin{tabular}{|c|c|c|c|c|c|}
\hline \multirow[b]{2}{*}{ Variable } & & \multicolumn{2}{|c|}{ Univariate } & \multicolumn{2}{|c|}{ Multivariate } \\
\hline & & OR $(95 \% \mathrm{CI})$ & $p$-Value & OR $(95 \% \mathrm{CI})$ & $p$-Value \\
\hline \multirow[t]{2}{*}{ Age } & $\geq 60$ Years & $1.38(0.59-3.19)$ & 0.46 & & \\
\hline & $<60$ Years & Reference & & & \\
\hline \multirow[t]{2}{*}{ BMI } & $\geq 23.5 \mathrm{~kg} / \mathrm{m}^{2}$ & $2.00(0.89-4.49)$ & 0.09 & & \\
\hline & $<23.5 \mathrm{~kg} / \mathrm{m}^{2}$ & Reference & & & \\
\hline \multirow[t]{2}{*}{ Treatment } & RAPN & $0.94(0.42-2.10)$ & 0.88 & & \\
\hline & PCA & Reference & & & \\
\hline \multirow[t]{2}{*}{ Single kidney } & Yes & $1.45(0.09-23.87)$ & 0.79 & & \\
\hline & No & Reference & & & \\
\hline \multirow[t]{2}{*}{ ASA-PS } & $\geq 2$ & $0.65(0.30-1.46)$ & 0.3 & & \\
\hline & $<2$ & Reference & & & \\
\hline \multirow[t]{2}{*}{ Preoperative eGFR } & $<70 \mathrm{ml} / \mathrm{min} / 1.73 \mathrm{~m}^{2}$ & $1.38(0.59-3.19)$ & 0.46 & & \\
\hline & $\geq 70 \mathrm{ml} / \mathrm{min} / 1.73 \mathrm{~m}^{2}$ & Reference & & & \\
\hline \multirow[t]{2}{*}{ Maximum tumour diameter } & $\geq 20 \mathrm{~mm}$ & $3.00(1.22-7.38)$ & 0.013 & $2.54(1.00-6.44)$ & 0.044 \\
\hline & $<20 \mathrm{~mm}$ & Reference & & Reference & \\
\hline \multirow[t]{2}{*}{ RENAL nephrometry score } & $\geq 8$ & $3.37(1.43-7.95)$ & 0.0046 & $2.94(1.22-7.08)$ & 0.015 \\
\hline & $<8$ & Reference & & Reference & \\
\hline
\end{tabular}

ASA-PS: American Society of Anesthesiologists physical status; BMI: body mass index; CI: confidence interval; eGFR: estimated glomerular filtration rate; OR: odds ratio; PCA: percutaneous cryoablation; RAPN: robot-assisted partial nephrectomy. Statistically significant $p$-values are shown in bold.

In the univariate analysis, preoperative eGFR $(>70$ $\left.\mathrm{ml} / \mathrm{min} / 1.73 \mathrm{~m}^{2}\right)$, maximum tumour diameter $(<20 \mathrm{~mm})$, and R.E.N.A.L nephrometry score $(<8)$ were significantly associated with trifecta achievement (Table III). Multivariate analysis also demonstrated that a R.E.N.A.L nephrometry score $(<8)$ was significantly associated with trifecta achievement [odds ratio $(\mathrm{OR})=4.20,95 \%$ confidence intervaI $(\mathrm{CI})=1.38-12.54 ; p=0.011]$.

Renal function outcomes. Changes in renal function after treatment in both groups are shown in Figure 1. The median eGFR preservation rate of the RAPN group was not significantly different from that of the PCA group at any time point ( 3 months: $p=0.18,6$ months: $p=0.96$, and 12 months: $p=0.51)$. In the univariate analysis, maximum tumour diameter $\geq 20 \mathrm{~mm}$ and R.E.N.A.L. nephrometry score $\geq 8$ were significantly associated with a decline in eGFR of $>10 \%$ at 6 months after surgery (Table IV). Multivariate analysis also revealed that maximum tumour diameter $\geq 20 \mathrm{~mm}(\mathrm{OR}=2.54,95 \% \mathrm{CI}=1.00-6.44$; $p=0.044)$ and R.E.N.A.L nephrometry score $\geq 8$ ( $\mathrm{OR}=2.94$; $95 \% \quad \mathrm{CI}=1.22-7.08 ; \quad p=0.015) \quad$ were significantly associated with a decline in eGFR of $>10 \%$ at 6 months after surgery.

Oncologic outcomes. The median follow-up was 18.5 months (IQR=12-30 months) for RAPN and 12 months (IQR=6-32 months) for PCA $(p=0.039)$. No perioperative

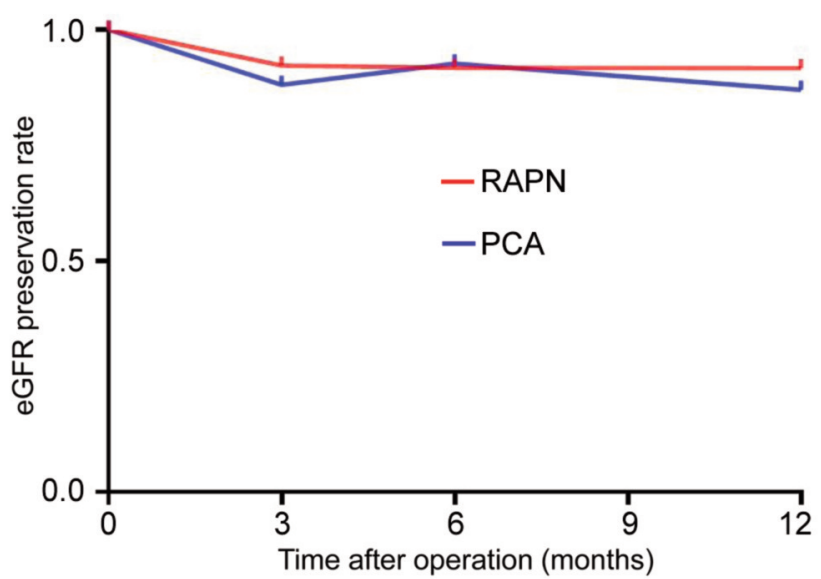

Figure 1. The rate of preservation of the estimated glomerular filtration rate (eGFR) after robot-assisted partial nephrectomy (RAPN) and percutaneous cryoablation (PCA).

deaths occurred in either group. Two and three local recurrences were observed in the RAPN and PCA groups, respectively. No metastasis occurred in either group. For survival analysis, the PCA group had a similar 3-year RFS rate to the RAPN group (90.3\% versus $93.5 \%, p=0.093$; Figure 2A). The 3-year OS rate was $100 \%$ [95\% CI=not reached] for RAPN and $97.4 \%$ for PCA $(95 \% \mathrm{CI}=$ not reached) ( $p=0.17$; Figure $2 \mathrm{~B})$. 

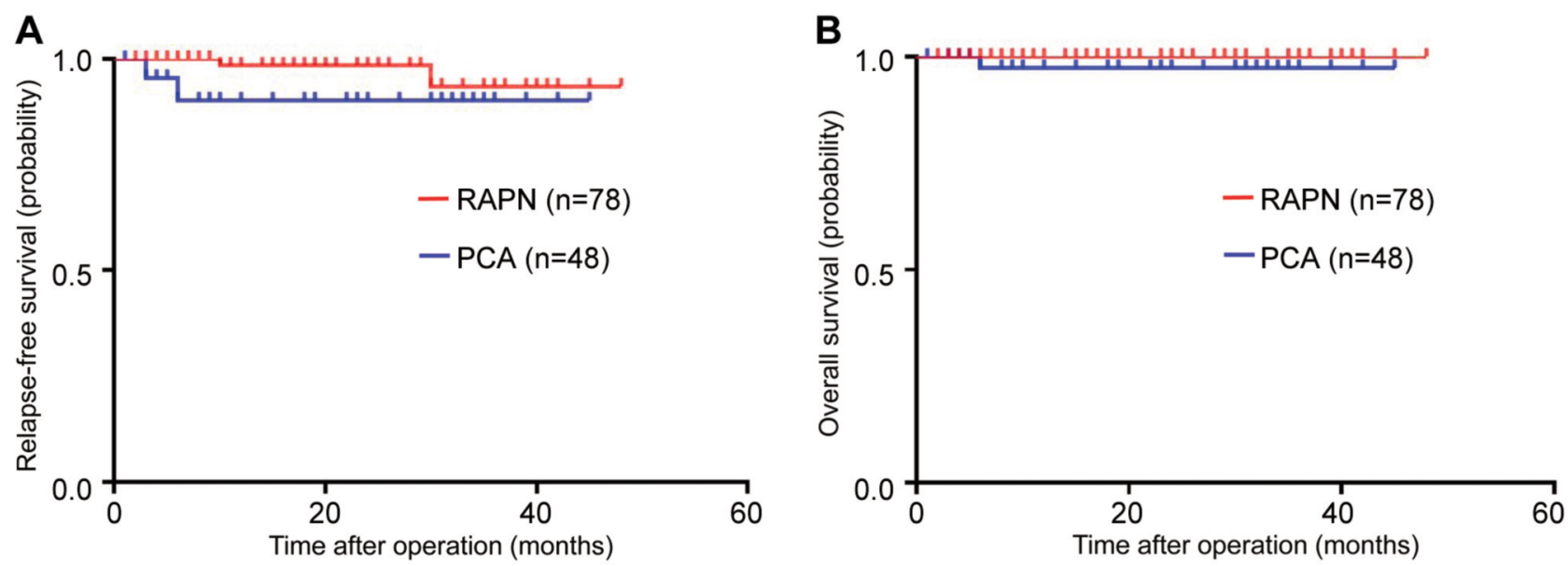

Figure 2. Relapse-free (A) and overall (B) survival curves after robot-assisted partial nephrectomy (RAPN) and percutaneous cryoablation (PCA).

\section{Discussion}

For surgical treatment of cT1 RCC, NST including PN has been the standard treatment because it is not only effective in cancer treatment but also reduces the incidence of cardiovascular events and mortality more effectively than radical nephrectomy does by preserving renal function and preventing chronic kidney disease $(3,15,16)$. Recently, RAPN has been widely used for NST and has shown promising clinical outcomes by shortening the warm ischaemia time and reducing perioperative complications (5, 6). On the other hand, according to the American Urological Association guidelines, thermal ablation such as PCA or radiofrequency ablation is an appropriate alternative treatment to $\mathrm{PN}$ in patients who are poor surgical candidates but need active treatment (17). To date, there are only a few comparative studies on treatment outcomes, especially on the preservation of renal function, between RAPN and PCA. Hence, in this study, we performed a data analysis of patients with cT1a RCC treated with RAPN or PCA and provided some evidence on oncological outcomes and renal function.

Firstly, in the results of our analysis of the RAPN group, the trifecta achievement rate was $52.6 \%$, which was similar to that in previous reports $(5,18,19)$. Sharma et al. reported that the R.E.N.A.L nephrometry score is a useful tool for determining renal tumour complexity (20). In the present study, we also found that the R.E.N.A.L nephrometry score was the decisive factor influencing trifecta achievement (21). Regarding perioperative complications, we observed no serious complications (Clavien-Dindo grade 4 or more) in either group. Our results are in line with data published by Rai et al. who reported no significant differences in the overall and Clavien-Dindo grade 3 or more complication rates between RAPN and cryoablation (22).
Secondly, although preoperative eGFR was significantly higher in the RAPN group than in the PCA group, there were no significant differences in the percentage of eGFR preservation between the two groups throughout the year. Our study is in concordance with Zargar et al., who reported that PN and CA had similar results in terms of preservation of renal function (23). These findings support the theory that RAPN and PCA have equivalent outcomes for medium-term renal function preservation in patients with cT1a RCC.

Thirdly, we found that there was no significant difference in RFS and OS rates between the RAPN and PCA groups during the medium term of 3 years. Caputo et al. reported contradictory outcomes in that RFS following RAPN was superior to that following CA (PCA and laparoscopic CA). We speculate that this difference may be due to the clinical stage of RCC (cT1b) (24). Our findings partially align with those reported by Tanagho and colleagues, who reported RAPN was superior to CA in disease-free survival but equivalent in OS and cancer-specific survival rates (25). Given these findings, RAPN and PCA are believed to be equivalent in terms of oncological outcomes during the medium-term in patients with cT1a RCC, although further investigations are needed to validate these results in the longer term.

This study had some limitations. Firstly, we performed a retrospective study with a limited number of patients. Secondly, split renal function should be further measured using a renogram in future trials. Thirdly, the present study did not assess long-term oncological outcomes.

\section{Conclusion}

In cT1a RCC, oncological outcomes and renal function after surgery appear to be similar in patients who undergo RAPN and those who undergo PCA, at least in the medium term. 
These findings indicate that PCA is an effective, minimally invasive treatment option for patients with cT1a RCC.

\section{Conflicts of Interest}

The Authors declare no competing financial interests.

\section{Authors' Contributions}

TU conceived the study, collected and analysed the patient data, and contributed to writing the manuscript. TK was responsible for the study conception and design and conducted the study, data collection and analysis, and drafting of the article. AN, AK, KH and TU performed the data analysis and provided scientific advice. YO, $\mathrm{HH}$ and NT performed cryoablation and completed the study. KF, $\mathrm{SF}, \mathrm{HK}, \mathrm{RI}, \mathrm{NN}$ and MU performed robot-assisted partial nephrectomy and completed the study. All Authors read and approved the final article.

\section{References}

1 Crépel M, Jeldres C, Sun M, Lughezzani G, Isbarn H, Alasker A, Capitanio U, Shariat SF, Arjane P, Widmer H, Graefen M, Montorsi F, Perrotte P and Karakiewicz PI: A population-based comparison of cancer-control rates between radical and partial nephrectomy for T1A renal cell carcinoma. Urology 76(4): 883888, 2010. PMID: 20932408. DOI: 10.1016/j.urology.2009.08.028

2 MacLennan S, Imamura M, Lapitan MC, Omar MI, Lam TB, Hilvano-Cabungcal AM, Royle P, Stewart F, MacLennan G, MacLennan SJ, Canfield SE, McClinton S, Griffiths TR, Ljungberg B, N'Dow J, UCAN Systematic Review Reference Group and EAU Renal Cancer Guideline Panel: Systematic review of oncological outcomes following surgical management of localised renal cancer. Eur Urol 61(5): 972-993, 2012. PMID: 22405593. DOI: 10.1016/j.eururo.2012.02.039

3 McKiernan J, Simmons R, Katz J and Russo P: Natural history of chronic renal insufficiency after partial and radical nephrectomy. Urology 59(6): 816-820, 2002. PMID: 12031359. DOI: $10.1016 / \mathrm{s} 0090-4295(02) 01501-7$

4 Van Poppel H, Da Pozzo L, Albrecht W, Matveev V, Bono A, Borkowski A, Colombel M, Klotz L, Skinner E, Keane T, Marreaud S, Collette S and Sylvester R: A prospective, randomised EORTC intergroup phase 3 study comparing the oncologic outcome of elective nephron-sparing surgery and radical nephrectomy for low-stage renal cell carcinoma. Eur Urol 59(4): 543-552, 2011. PMID: 21186077. DOI: 10.1016/ j.eururo.2010.12.013

5 Choi JE, You JH, Kim DK, Rha KH and Lee SH: Comparison of perioperative outcomes between robotic and laparoscopic partial nephrectomy: a systematic review and meta-analysis. Eur Urol 67(5): 891-901, 2015. PMID: 25572825. DOI: 10.1016/ j.eururo.2014.12.028

6 Wu Z, Li M, Liu B, Cai C, Ye H, Lv C, Yang Q, Sheng J, Song S, Qu L, Xiao L, Sun Y and Wang L: Robotic versus open partial nephrectomy: a systematic review and meta-analysis. PLoS One 9(4): e94878, 2014. PMID: 24740259. DOI: 10.1371/ journal.pone.0094878

7 Georgiades CS and Rodriguez R: Efficacy and safety of percutaneous cryoablation for stage $1 \mathrm{~A} / \mathrm{B}$ renal cell carcinoma: results of a prospective, single-arm, 5-year study. Cardiovasc Intervent Radiol 37(6): 1494-1499, 2014. PMID: 24385225. DOI: $10.1007 / \mathrm{s} 00270-013-0831-8$

8 Thompson RH, Atwell T, Schmit G, Lohse CM, Kurup AN, Weisbrod A, Psutka SP, Stewart SB, Callstrom MR, Cheville JC, Boorjian SA and Leibovich BC: Comparison of partial nephrectomy and percutaneous ablation for $\mathrm{cT} 1$ renal masses. Eur Urol 67(2): 252-259, 2015. PMID: 25108580. DOI: $10.1016 / j$.eururo.2014.07.021

9 Dindo D, Demartines $\mathrm{N}$ and Clavien PA: Classification of surgical complications: a new proposal with evaluation in a cohort of 6336 patients and results of a survey. Ann Surg 240(2): 205-213, 2004. PMID: 15273542. DOI: 10.1097/01.sla. 0000133083.54934.ae

10 Clavien PA, Barkun J, de Oliveira ML, Vauthey JN, Dindo D, Schulick RD, de Santibañes E, Pekolj J, Slankamenac K, Bassi C, Graf R, Vonlanthen R, Padbury R, Cameron JL and Makuuchi M: The Clavien-Dindo classification of surgical complications: five-year experience. Ann Surg 250(2): 187-196, 2009. PMID: 19638912. DOI: 10.1097/SLA.0b013e3181b13ca2

11 Hung AJ, Cai J, Simmons MN and Gill IS: "Trifecta" in partial nephrectomy. J Urol 189(1): 36-42, 2013. PMID: 23164381. DOI: $10.1016 /$ j.juro.2012.09.042

12 Komninos C, Shin TY, Tuliao P, Han WK, Chung BH, Choi YD and Rha KH: Renal function is the same 6 months after robotassisted partial nephrectomy regardless of clamp technique: analysis of outcomes for off-clamp, selective arterial clamp and main artery clamp techniques, with a minimum follow-up of 1 year. BJU Int 115(6): 921-928, 2015. PMID: 25376793. DOI: 10.1111/bju.12975

13 Guillotreau J, Haber GP, Autorino R, Miocinovic R, Hillyer S, Hernandez A, Laydner H, Yakoubi R, Isac W, Long JA, Stein RJ and Kaouk JH: Robotic partial nephrectomy versus laparoscopic cryoablation for the small renal mass. Eur Urol 61(5): 899-904, 2012. PMID: 22264680. DOI: 10.1016/j.eururo.2012.01.007

14 Kutikov A and Uzzo RG: The R.E.N.A.L. nephrometry score: a comprehensive standardized system for quantitating renal tumor size, location and depth. J Urol 182(3): 844-853, 2009. PMID: 19616235. DOI: 10.1016/j.juro.2009.05.035

15 Thompson RH, Boorjian SA, Lohse CM, Leibovich BC, Kwon $\mathrm{ED}$, Cheville JC and Blute ML: Radical nephrectomy for pT1a renal masses may be associated with decreased overall survival compared with partial nephrectomy. J Urol 179(2): 468-471; discussion 472-473, 2008. PMID: 18076931. DOI: 10.1016/ j.juro.2007.09.077

16 Huang WC, Elkin EB, Levey AS, Jang TL and Russo P: Partial nephrectomy versus radical nephrectomy in patients with small renal tumors - is there a difference in mortality and cardiovascular outcomes? J Urol 181(1): 55-61; discussion 612, 2009. PMID: 19012918. DOI: 10.1016/j.juro.2008.09.017

17 Campbell S, Uzzo RG, Allaf ME, Bass EB, Cadeddu JA, Chang A, Clark PE, Davis BJ, Derweesh IH, Giambarresi L, Gervais DA, Hu SL, Lane BR, Leibovich BC and Pierorazio PM: Renal Mass and Localized Renal Cancer: AUA Guideline. J Urol 198(3): 520-529, 2017. PMID: 28479239. DOI: 10.1016/ j.juro.2017.04.100

18 Lavery HJ, Small AC, Samadi DB and Palese MA: Transition from laparoscopic to robotic partial nephrectomy: the learning curve for an experienced laparoscopic surgeon. JSLS 15(3): 291-297, 2011. PMID: 21985712. DOI: 10.4293/108680811X13071180407357 
19 Lucas SM, Mellon MJ, Erntsberger L and Sundaram CP: A comparison of robotic, laparoscopic and open partial nephrectomy. JSLS 16(4): 581-7, 2012. PMID: 23484568. DOI: $10.4293 / 108680812 X 13462882737177$

20 Sharma AP, Mavuduru RS, Bora GS, Devana SK, Singh SK and Mandal AK: Predicting trifecta outcomes after robot-assisted nephron-sparing surgery: Beyond the nephrometry score. Investig Clin Urol 59(5): 305-312, 2018. PMID: 30182075. DOI: 10.4111/icu.2018.59.5.305

21 Lee KS, Kim DK, Kim KH, Bang WJ, Kim HJ, Park SY, Rha $\mathrm{KH}$, Chung BH, Cho JS and Koo KC: Predictive factors for the development of renal insufficiency following partial nephrectomy and subsequent renal function recovery: A multicenter retrospective study. Medicine (Baltimore) 98(18): e15516, 2019. PMID: 31045843. DOI: 10.1097/MD. 0000000000015516

22 Rai BP, Jones P, Tait C, Amitharaj R, Gowda R, Bhatti A, Adshead $\mathrm{J}$ and Somani B: Is cryotherapy a genuine rival to robotic-assisted partial nephrectomy in the management of suspected renal malignancy? A systematic review and metaanalysis. Urology 118: 6-11, 2018. PMID: 28962877. DOI: 10.1016/j.urology.2017.09.008
23 Zargar H, Atwell TD, Cadeddu JA, de la Rosette JJ, Janetschek G, Kaouk JH, Matin SF, Polascik TJ, Zargar-Shoshtari K and Thompson RH: Cryoablation for small renal masses: selection criteria, complications, and functional and oncologic results. Eur Urol 69(1): 116-128, 2016. PMID: 25819723. DOI: 10.1016/ j.eururo.2015.03.027

24 Caputo PA, Zargar H, Ramirez D, Andrade HS, Akca O, Gao T and Kaouk JH: Cryoablation versus Partial Nephrectomy for clinical T1b renal tumors: A matched group comparative analysis. Eur Urol 71(1): 111-117, 2017. PMID: 27568064. DOI: 10.1016/j.eururo.2016.08.039

25 Tanagho YS, Bhayani SB, Kim EH and Figenshau RS: Renal cryoablation versus robot-assisted partial nephrectomy: Washington University long-term experience. J Endourol 27(12): 1477-1486, 2013. PMID: 24283518. DOI: 10.1089/end.2013.0192

Received January 14, 2021

Revised February 10, 2021

Accepted February 11, 2021 